\title{
What the scientists say
}

\section{Russian researchers, and those who have worked in Russia, share their thoughts with Nature on the problems faced by the country's scientific system - and how they could be addressed.}

\author{
Alexander Sobolev \\ Geochemist, Vernadsky Institute of \\ Geochemistry and Analytical Chemistry, \\ Russian Academy of Sciences (RAS), \\ Moscow. Corresponding member, RAS
}

According to the citation-analysis company Thomson Scientific, Russia is eighteenth among countries ranked by citations in the scientific literature over the past 10 years. That is a result not just of low overall funding but because management of basic science still stands on the concepts of a closed society, with a centralized administration inherited from the days of the Soviet Union. This leads to the absence of international peer review and to little motivation for scientists to produce international-level scientific results - they do not really need them to get funding from national sources. In addition, centralized funding of institutions, rather than of individual scientists, leads to resources

being wasted.
Compared with the Soviet
"Russia needs a
nationwide initiative
to restore its
scientific
potential."

Union, Russia today is quite an open society and has had to adjust its national science to the international level. But so far only timid steps have been made in this direction. The Russian Foundation for Basic Research, set up in 1992, is still almost the only source of peer-reviewed funding for individual natural scientists in the country. It suffers from a shortage of competent experts, and provides insufficient support - up to only US $\$ 15,000$ per year per project.

I think Russia needs a nationwide initiative, concentrating on personnel rather than specific technological goals, to restore its scientific potential. I would start by establishing an international peer-review expert system. The core of this should be formed by Russian scientists both inside and outside the country - who are producing internationally recognized results.

The next step would be to concentrate funding on individual scientists and groups who operate at the international level. This should include open competition for adequately funded permanent positions and 'soft money' grants based on international peer review. It would also mean creating 'centres of excellence' to support efficient groups with infrastructure and equipment. These ideas are already being discussed by Russia's scientific community (see www.scientific.ru), and I hope they will finally be considered by the authorities.

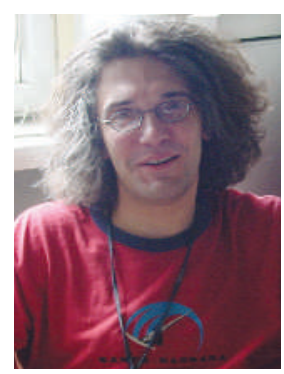

\section{Konstantin Severinov}

Waksman Institute of Microbiology, Rutgers University, New Jersey. Institute of Molecular Genetics, Russian Academy of Sciences, Moscow

Russian biological science has a proud history, with greats such as Ivan Pavlov and Nikolai Koltsov, and successful emigrés including George Gamow and Theodore Dobzhansky. Despite Stalin's purges of the 1930s and 1940s, by the 1970s the country had the nucleus of a thriving life-sciences community. A precipitous decline in funding conditions in the 1990s caused many active scientists to leave the country. This brain drain is only now beginning to slow, thanks to the recent flush of petrodollars, but significant problems remain.

Basic research in biology is deemed unnecessary by Russian society, even more so now that scientists' salaries are starting to increase and society expects immediate practical results in return. Russia has no modern biotechnology industry to speak of, so there is little demand to exploit basic-science results. A scientific superstar might raise the profile of basic research. But without a vibrant scientific community, and with problems in getting reagents and sending materials abroad, such a star is unlikely to emerge in Russia.

Nevertheless, the nostalgic view of great Russian science is deeply ingrained in the public mind. To return to this greatness, the government has developed grandiose programmes such as the multibillion-dollar nanotechnology initiative. Although welcome, this influx of money may also make science attractive to profiteers doing bad (or pseudo) science.
Certain survivors of the 1990s who stayed in the country and remained in science are now fashioning themselves as 'keepers of the flame'. They are moving to top administrative positions in the institutes. Some tend to be conservative and against the use of bibliometric data to measure productivity. Some propagate the myth that editors of international journals are prejudiced against Russian scientists. As a result, a significant number of students who stay in the country end up doing science of dubious value.

At least one programme at the Russian Academy of Sciences, in molecular and cellular biology, is giving generous three- and fiveyear grants to individual groups, including new groups set up by returning Russian scientists. But establishing financially and scientifically independent labs in academy institutes goes against the general idea of centralization in present-day Russia - so it is unclear how long such labs will last.

\section{Mikhail Kovalchuk}

Director, Russian Research Centre Kurchatov Institute, Moscow. Acting vicepresident the Russian Academy of Sciences (RAS). Corresponding member, RAS

Over the decades, Russia has initiated a lot of important fields in world science and technology, including atomic energy, nuclear fusion and space exploration. Despite the financial troubles of the past 20 years, science in Russia has continued to develop, thanks to the intellectual and material reserves from the Soviet period. Our research has become integrated in the world scientific community.

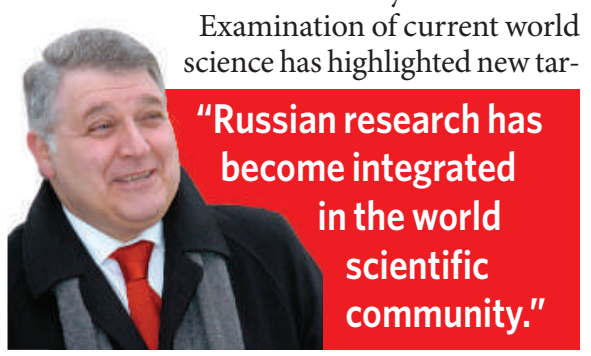

gets for scientific and technical development, which has led Russia to rethink its approach and has generated a new state policy on science and technology.

World science now is characterized by a movement towards technologies of atomic or 
molecular design, combining modern microelectronics with biological structures. This merging of disciplines needs to be reflected in the scientific expertise. Russia's present science and education system, which fosters narrow specialization, must be replaced by a system based on interdisciplinary research.

The simplest and most effective model for such a development would be to set up national scientific laboratories. In Russia this is now being piloted with the nanotechnology project at the Kurchatov Institute. An international network of such research centres, based on national laboratories, could be the foundation of a new global system of scientific and educational organization.

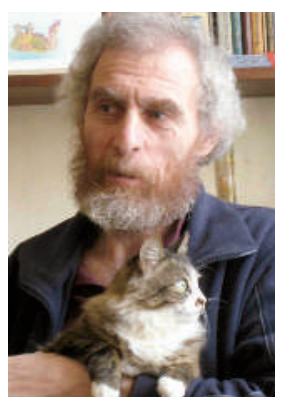

\section{Mikhail Feigel'man Physicist, L. D.} Landau Institute for Theoretical Physics, Russian Academy of Sciences, Moscow

There are five big problems for fundamental research in Russia. First, the salaries of researchers are still far too low: the official salary of a full professor at an academic research institute in Moscow is about one-third of the average income in the city. Second, although funds for modern research equipment have, in principle, become available over the past few years, distribution of this money is irresponsible - it usually goes to 'big shots' not doing real science. Third, the top brass of the Russian Academy of Sciences has been unable to start long-anticipated reforms of its own organization. Fourth, government officials responsible for reconstructing the scientific infrastructure have often been simply incompetent. And fifth, the federal secret service has accused numerous Russian scientists of espionage, with obvious falsifications.

The result is that the number of internationally competitive groups has seriously diminished in the past 15 years. The few that have survived could potentially seed a revival of physics in Russia. The key problem is the lack of a generally recognized system of research evaluation. There is no well defined procedure to distinguish really good science from pure trash.

What can be done for recovery? First, the system of research evaluation can and must be constructed by the scientific community itself, using the very modest financial means provided by non-governmental sources. Second, Russian business interests could be approached for help, as they want to develop a national high-tech industry. Third, real face-to-face international cooperation between specific labs and between scientists in Russia and those abroad should be encouraged as much as possible.

Taking all that together, we can probably survive some more years - with hope for a more adequate Russian government to come, eventually, and to do its job in rebuilding the national science system.

\section{Rebecca Frumkina}

Institute of Linguistics, Russian Academy of Sciences, Moscow

Although I am more than 75 years old, I am still an active academic. This means that I am considered socially successful and, by all formal standards, I should have nothing to complain about. In fact, I am deeply concerned about the future of Russian science - and here I use the term 'science' to encompass both science and the humanities.

Science is a social institution. As such, it has its own laws and specific means of interaction with other social institutions. So science should not be treated as an enterprise that needs an external crisis manager to make ends meet. Nevertheless, this is exactly what state policy does - examples include attempts to quash even the slightest signs of autonomy at the Russian Academy of Sciences; the reduction of money for fundamental research; and the cutbacks and neglect at the National Library.

Young people who wish to become academics will go on leaving this country until the state changes its position on fundamental aspects of

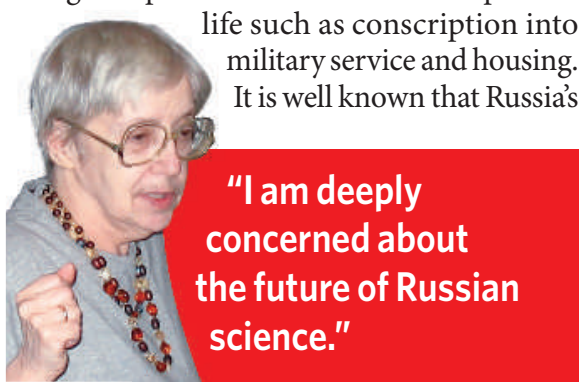

academics are underpaid, so I am not surprised that nearly all my former postgraduates either left science here for, say, the media or advertising, or have left this country to join companies such as Microsoft, Hewlett-Packard or IBM.

I reject the prospect of obligatory EGE exams for students attempting to enter university, as well as Russia's plans to join the Bologna process, which aims to standardize university degrees across Europe. In Russia we do not have a stable education system leading to formal degrees such as a BA, MA, BSc or MSc. We need to have a stable system in place before we can be ready to standardize our academic degrees. Otherwise, all efforts will be counterproductive.

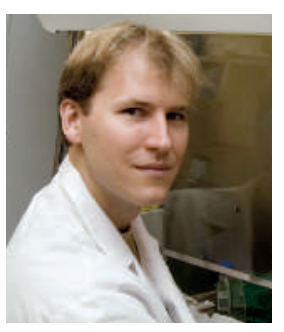

Jens Kuhn

German virologist, New England Primate Research Center, Massachusetts

Russian virology is not typically held in high esteem by most Western scientists. Almost certainly this is because in the West, the quality of research is mainly defined by the impact factor ascribed to the publishing journal. Consequently, articles published in journals with low impact factors, such as the majority of Russian virology contributions, are considered mediocre science in the United States and Europe. This assessment is unjustly biased.

Russian virological data are frequently published in journals not indexed in PubMed, which, sadly, is often the only database used by Western scientists. Political, rather than scientific, factors - perhaps patriotism or the demands of the still ever-present state-security apparatus - often drive Russians to publish their data in national journals in the Russian language. Furthermore, publication in a journal with a high impact factor is often facilitated by state-of-the-art technology, which can rarely be afforded by Russian laboratories. Limited finances may mean a shortage of reagents and outdated equipment. But taking a careful look at what is being published under these dire conditions, one can only be impressed by the skills and creativity of many Russian researchers. For instance, my search of libraries has shown that the majority of the world's scientific literature on both Crimean-Congo and Omsk haemorrhagic fevers has been published in Russian, but most of it has not been indexed in PubMed.

It is true that much of this literature is not cutting-edge molecular biology — but in terms of epidemiological, clinical and pathological data, Russian science equals literature from Western labs. As for molecular-biological data, there are excellent and pioneering publications devoted to genomic sequencing of tick-borne encephalitis, Marburg and smallpox viruses. Of course, it should not be forgotten that, especially in pathogen research, good-quality Russian research often sprouted from 'bad' circumstances - namely, the Soviet Union's biowarfare programme, which was terminated more than a decade ago. Various international grant-assistance programmes are helping to redirect former biowarfare facilities into public health; and international scientist exchanges, such as the one in which I participated in Russia, are boosting this process (see Nature 423, 679; 2003).

There is much to be learnt from Russian researchers, and the West should do all it can 
to support peaceful Russian science both financially and collaboratively — rather than be arrogant and ignore its important contributions.

\section{Roald Sagdeev}

Physicist, University of Maryland. Full member, Russian Academy of Sciences

As we commemorate the fiftieth anniversary of Sputnik, should we feel nostalgic for the past grandeur of Soviet science? Sputnik's historic launch took place only a year after Stalin's cult of personality was denounced by Khrushchev. Science back then was simply a servant of the regime. Research areas related to defence received a disproportionate amount of state support; the rest, at best, was on a sort of welfare. The government invested in expanding the infrastructure by building science cities (akademgorodoks). Khrushchev's successor, Brezhnev, declared science to be a "productive force of society". But the productivity of researchers was limited by factual isolation from international science, and by tight ideological and administrative control.

The dismantling of the Soviet Union has brought tangible fruits of globalization to the Russian scientific community. Researchers now have the chance to become part of world science and to look for work outside the country. But, ironically, the dividends of freedom have not led to many more opportunities at home.

If the impediment to science investment in the early 1990s was coping with the economic cataclysm of the post-communist transition, today it is the need to adapt to the difficult realities of the market economy. That requires deep institutional and structural changes in the organization of Russia's research and development; changes that should see funding distributed fairly to

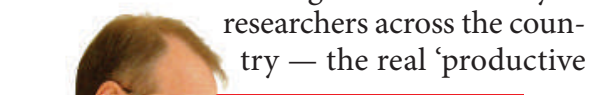

"Reforms are needed to bring back Russia's estranged scientists."
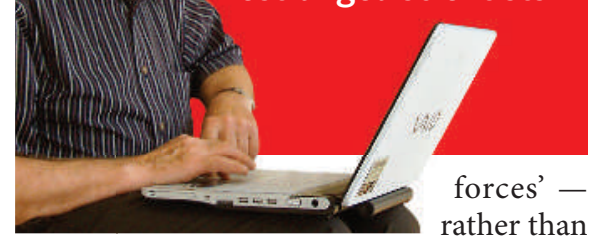

forces' rather than being made available to only a privileged few. Fundamental research and large projects in applied science will need stronger support from the state, similar to that already provided for Russia's participation in the international fusion-energy experiment, ITER, and now promised for nanotechnology.

Contemporary science culture is quite cosmopolitan. Scientists are choosing the places most conducive to the application of their talents. Reforms that provide real, rather than simply declared on paper, successes in Russia are needed to bring back her estranged scientists. By doing so, Russia could perhaps achieve even more and attract the best foreign brains. Wasn't such a thing done in the eighteenth century by Peter the Great? After all, today's Russia is richer and already allows herself to recruit expensive foreign sports stars.

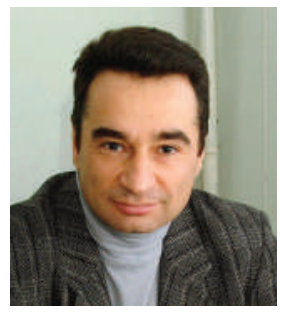

Simon Lyakhovich Theoretical physicist, Tomsk State University

The period after the collapse of the Soviet Union can be divided into two stages. From 1992 to 2002, a new system was established that was characterized by calls for research projects or grants that would be awarded on the basis of peer review. During this turbulent period, resources were limited, and the social environment was not conducive to doing fundamental research. As a result, individuals would typically make extended research visits to the West. But what is rarely recognized is that the opinion of the scientific community mattered in this system, and that scientific excellence was a criterion in selecting which projects or teams received support. Even with limited resources, shaky institutions, immature mechanisms, and multiple mistakes and abuses, this system delivered some impressive results.

Starting around 2003, the research-oriented team system was replaced by an administration-oriented one, based on new oil and gas wealth, and built on the new social order in the country. Organizations and administrative ranks are now the key aspects. Russian funding sources are growing rapidly, but the funds are now directed to organizations far more than to research teams. Selection decisions on the huge grants are made through negotiations with the director of the host organization rather than through serious independent evaluation of the scientific quality of the proposal and the research team. And location now plays an increasing role: in the extremely centralized administrative system, Moscow and St Petersburg scientists have better opportunities, on average, than their colleagues elsewhere.

The flow of talent to the best universities outside these two cities has begun to decrease. But the cost of attracting student talent is not high. For example, the 20 best universities could be boosted by establishing 100 stipends per university to attract talented students from other cities. These stipends would each cost only US $\$ 400$ per month - so the cost of the overall programme would be almost nothing compared with the funds spent on the inefficient mega projects of the new era.

\section{Evgeny Antipov \\ Chemist, Moscow State University}

The biggest challenge facing the Russian scientific community is the government's attempt to start an immediate breakthrough in innovative technologies by significantly increasing funding. This move may sound very promising, but after 20 years of financial starvation our scientific community has become very inhomogeneous. Only a few groups have been able to maintain the universally accepted international research level and can win competitive international grants.

The existing funding system in Russia is inefficient and ignores international standards. The government's desire to move beyond development based on natural resources will not be realized with the simple formula 'more money = better science'. What needs to be done is to establish trusted scientific expertise to evaluate the quality of research and therefore the fields of science and groups to be funded. That expertise would be based on accepted international criteria, such as quality of publications, citations and scientific reputation in the international community. It would modify the formula to be 'more money = better scientific expertise $=$

\section{"The existing funding system in Russia is inefficient."}

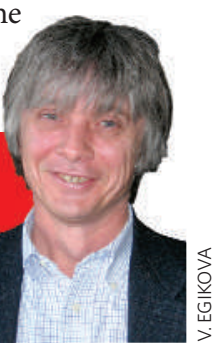

better science.' Such an approach would stop the support of low-quality research, which creates no real base for innovation.

I see another challenge in establishing solid links with fast-developing private companies. These have already started investing to develop new products and to improve existing technologies, but have encountered the same problem: how to identify people who can do high-quality research. Many of them prefer to buy advanced technologies from abroad; fortunately, some companies continue their search for scientists in Russia. For instance, Moscow State University and the United Company RUSAL (one of the main aluminium producers) last year established a joint lab to develop the basics of aluminium production. It was one step towards the 'revival' of our science - I hope it is not the last.

See also pages 507 and 536. 